\title{
Psychiatric morbidity and quality of life in children and adolescents with cystic fibrosis
}

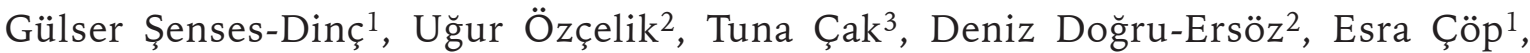 \\ Ebru Yalçın², Ebru Çengel-Kültür ${ }^{3}$, Sevgi Pekcan, Nural Kiper ${ }^{4}$, Fatih Ünal ${ }^{3}$ \\ ${ }^{1}$ Clinics of Child and Adolescent Psychiatry, Ministry of Health Ankara Children's Health and Pediatric Hematology- \\ Oncology Training and Research Hospital, Departments of ${ }^{2}$ Pulmonology and ${ }^{3}$ Child and Adolescent Psychiatry, Hacettepe \\ University Faculty of Medicine, Ankara, and ${ }^{4}$ Pediatric Pulmonology, Selcuk University Meram Faculty of Medicine, Konya, \\ Turkey. E-mail: gulserdinc@yahoo.com
}

Received: 14th June 2017, Revised: 7th August 2017, Accepted: 30th August 2017

SUMMARY: Şenses-Dinç G, Özçelik U, Çak T, Doğru-Ersöz D, Çöp E, Yalçın E, Çengel-Kültür E, Pekcan S, Kiper N, Ünal F. Psychiatric morbidity and quality of life in children and adolescents with cystic fibrosis. Turk J Pediatr 2018; 60: 32-40.

The aim of this study was to investigate psychiatric disorders, depression and anxiety levels, and quality of life in children and adolescents with cystic fibrosis (CF), and to compare them with those of children with non-cystic fibrosis (non-CF) bronchiectasis and healthy controls. A total of 103 children and adolescents aged 7-16 years (35 CF, 28 non-CF bronchiectasis, 40 healthy) were evaluated using The Schedule for Affective Disorders and Schizophrenia for School Aged Children (K-SADS), The Child Depression Inventory (CDI), The State-Trait Anxiety Inventories for Children (STAI-C) and the Pediatric Quality of Life Inventory (PedsQL)-C. The three groups were not statistically different with respect to age, sex, and familial sociodemographic variables. $80 \%$ of the children and adolescents in the CF group were diagnosed with a psychiatric disorder, which was significantly more compared to those of the two other groups. The CF group had significantly greater rates of depressive and oppositional defiant disorder and the non-bronchiectasis group had a significantly greater rate of anxiety disorder than the control group. The depression and anxiety symptom levels were significantly greater and the quality of life levels significantly lower in both the CF and non-CF bronchiectasis groups than the healthy controls. In the CF group, the presence of any associated psychiatric disorder led to significantly lower total and psychosocial quality of life scores. In conclusion, CF is associated with poorer QOL in childhood. In order to improve quality of life in CF, the psychiatric conditions of children and adolescents should also be evaluated and their follow-up and treatment should involve a multidisciplinary team approach.

Key words: cystic fibrosis, children, psychopathology, quality of life.

Cystic fibrosis (CF) is a genetic disorder with autosomal recessive transmission. Mutations in Cystic Fibrosis Transmembrane Regulator Gene result in diffuse dysfunction of exocrine glands, culminating in multi-organ involvement where the pulmonary involvement is the most common ${ }^{1}$. As the main cause of morbidity and mortality in CF is respiratory involvement, the main goal of treatment is pulmonary protection. ${ }^{1}$ In recent years, the advances in treatment approaches, and infection control have increased the average life expectancy of
CF patients. With increased life expectancy of children with $\mathrm{CF}$, they and their families now face different difficulties. A substantially serious course of the disease, the time-consuming nature of its treatment, serious limitation of daily activities, and prognostic uncertainties create immense stress in patients and their families. ${ }^{1,2}$

Although some studies have evaluated psychosocial adaptation and psychiatric morbidity in children and adolescents with $\mathrm{CF}$, their results are rather inconsistent. Some 
studies have reported adjustment problems, increased depression and anxiety levels, and a high rate of psychopathology in these children and adolescents ${ }^{3-5}$ whereas some others have indicated a comparable functionality with their healthy peers. 2,6,7 Studies so far have reported anxiety disorders, depression, and oppositional defiant disorder as psychiatric disorders in children and adolescents with CF. $3,8,9$

The concept of quality of life (QOL) is a multi-dimensional subjective assessment of one's own health and life. This concept encompasses various dimensions such as physical, psychological, and social wellness, and functionality. ${ }^{10}$ Modern interventions not only aim to provide a quantitative improvement, but also an improvement in quality of life. In $\mathrm{CF}$, many factors affect quality of life. So far, studies of children and adolescents with CF have usually investigated the relationship between quality of life and sociodemographic features and physical health-related factors. ${ }^{11-15}$ To date, many studies have examined the impact of a variety of clinical variables on QOL, which include pulmonary function tests (PFT), body mass index, infectious agents, hospitalization, malnutrition, and disease severity. ${ }^{12-15}$ Particulary, the forced expiratory volume $1\left(\mathrm{FEV}_{1}\right)$ value, which is used for determining the severity of the illness, has been widely expressed as a major factor affecting QOL.11-13 In adults, on the other hand, psychosocial factors have also been studied. Although it has been mostly reported that psychological symptom level was high and it adversely affected QOL in adults with $\mathrm{CF}, 4,16-18$ there is a paucity of studies examining psychosocial factors with potential serious consequences on QOL in children and adolescents with CF. In children and adolescents with CF, hopelessness about future, stigmatization perception, and school absenteeism have been related to an impaired quality of life.8,19,20

In these CF patients whose life expectancy has been prolonged, determining psychosocial factors affecting quality of life may bring about psychosocial interventions. As to the best of our knowledge, this study is the first to examine the relationship between psychiatric disorders diagnosed by a structured psychiatric interview and QOL in children and adolescents with
CF. This study aimed to evaluate psychiatric morbidity, the depression and anxiety levels, and QOLin children and adolescents with $\mathrm{CF}$, and to compare them with those of non-cystic fibrosis (non-CF) bronchiectasis and healthy control groups. Additionally, we aimed to determine the relationship between psychosocial factors and QOL.

\section{Material and Methods}

\section{Participants}

This study included a total of 35 volunteers aged 7-16 years who were at follow-up for CF at Hacettepe University Faculty of Medicine, Pediatric Pulmonology outpatient clinic for a period of 1 year. The control groups included 28 patients with non-CF bronchiectasis matched for age and sex, and followed in the same clinic, as well as 40 healthy subjects matched for age and sex, who presented to the outpatient clinics of Hacettepe University for any acute physical health problems.

\section{Measures}

The Socio-demographic and Clinical Information Questionnaire (SCIQ): This is a form developed by the researchers to be used for each participant in the study. The PFT [forced expiratory volume $1\left(\mathrm{FEV}_{1}\right)$, forced vital capacity (FVC), forced expiratory flow $\left.25-75 \%\left(\mathrm{FEF}_{25-75}\right)\right]$ of the patients in the $\mathrm{CF}$ and non CF-bronchiectasis groups were accessed via medical records.

Hollingshead-Redich Scale (HRS): Translated into Turkish by Kültür, the scale aims to determine a family's socioeconomic status (SES). ${ }^{21}$ The scale determines SES by taking into account the occupational and educational levels of both of the parents.

The Child Depression Inventory (CDI): This is a 27item self-reported scale that can be applied to children aged 6-17 years. ${ }^{22,23}$ It rates depressive symptoms in the last 2 weeks, with higher scores indicating more depressive symptoms.

The State-Trait Anxiety Inventories for Children (STAI-C): This is a self-reported scale composed of two subscales each with 20 items, and it rates state and trait anxiety levels of children. ${ }^{24,25}$ State anxiety refers to anxiety symptoms under certain circumstances and trait anxiety to permanent individual features creating a tendency for anxiety perception. Higher scores 
indicate a high anxiety level.

Schedule for Affective Disordersand Schizophrenia for School Aged Children-Present and Lifetime Version (K-SADS-PL): This is a semi-structured psychiatric interview applied by a clinician, which is developed to screen psychiatric disorders on the basis of DSM-III and DSM-IV diagnostic criteria in children and adolescents aged 6-18 years. ${ }^{26}$ The validity and reliability of the Turkish version was tested by Gökler et al. ${ }^{27} \mathrm{~K}-\mathrm{SADS}-\mathrm{PL}$ questions psychiatric disorders in accordance with the information obtained from the parents and the child, and the psychiatric diagnosis is made by incorporating the psychiatrist's observations.

The Pediatric Quality of Life Inventory Parent Version (PedsQL-P) and the Pediatric Quality of
Life Inventory Child Version (PedsQL-C): These were developed to rate health-related quality of lives of children and adolescents aged 2-18 years. ${ }^{10}$ It questions about the domains of physical health, emotional functionality, and social functionality, which are the properties of the state of healthiness as defined by the World Health Organization. This scale is being used in children with a variety of choronic medical conditions. It contains two subscales scores, namely psychosocial (PSH) and physical health $(\mathrm{PH})$, and a total health $(\mathrm{TH})$ score. The scale contains both parent and child versions for physical and psychosocial functioning, and a higher PedsQL total score indicates a better QOL. In this study, the PedsQL-P scale was administered to the caregiver. Memik et al. ${ }^{28,29}$

Table I. Sociodemographic Properties and Pulmonary Function Tests.

\begin{tabular}{|c|c|c|c|c|}
\hline & $\begin{array}{l}\text { CF } \\
(n=35)\end{array}$ & $\begin{array}{l}\text { Non-CF } \\
\text { bronchiectasis } \\
(\mathrm{n}=28)\end{array}$ & $\begin{array}{l}\text { Control } \\
(\mathrm{n}=40)\end{array}$ & \\
\hline \multicolumn{5}{|l|}{ Gender, n (\%) } \\
\hline Female & $15(42.9)$ & $13(46.4)$ & $19(47.5)$ & $\mathrm{x} 2=0.172$ \\
\hline Male & $20(57.1)$ & $15(53.6)$ & $21(52.5)$ & $\mathrm{p}=0.918$ \\
\hline Socioeconomic status, $\mathrm{n}(\%)$ & & $2(7.1)$ & $10(25.0)$ & \\
\hline High & $9(25.7)$ & $18(64.3)$ & $21(52.5)$ & $\mathrm{x} 2=6.343$ \\
\hline Medium & $14(40)$ & $8(28.6)$ & $9(22.5)$ & $\mathrm{p}=0.197$ \\
\hline Low & $12(34.3)$ & & & \\
\hline Age (months)* & $156(90-204)$ & $165(96-192)$ & $149(87-192)$ & $\begin{array}{l}x 2=1.496 \\
p=0.474\end{array}$ \\
\hline Maternal age (years)* & $37(30-48)$ & $41(28-49)$ & $40(33-49)$ & $\begin{array}{l}x 2=3.343 \\
p=0.190\end{array}$ \\
\hline Paternal age (years)* & $41(31-53)$ & $44(29-53)$ & $42(35-54)$ & $\begin{array}{l}x 2=2.001 \\
p=0.386\end{array}$ \\
\hline Maternal education (years) ${ }^{*}$ & $5(5-15)$ & $5(5-15)$ & $5(5-15)$ & $\begin{array}{l}x 2=1.905 \\
p=0.386\end{array}$ \\
\hline Paternal education (years)* & $8(5-15)$ & $9.5(5-15)$ & $11(5-15)$ & $x 2=1.630$ \\
\hline Hospitalization rate, n (\%) & $32(91.4)$ & $22(78.6)$ & - & $\mathrm{p}=0.435$ \\
\hline $\begin{array}{l}\text { Hospitalization number } \\
\text { (frequency)* }\end{array}$ & $6(1-30)$ & $2.5(1-15)$ & - & $\begin{array}{l}\mathrm{p}=0.170 \\
\mathrm{p}=0.138\end{array}$ \\
\hline $\begin{array}{l}\text { Hospitalization duration } \\
\text { (days)* }^{*}\end{array}$ & $22(3-300)$ & $20(1-180)$ & - & $\begin{array}{l}Z=-1.036 \\
p=0.300\end{array}$ \\
\hline $\mathrm{FEV}_{1}^{*}$ & $93(31-113)$ & $77.5(31-122)$ & - & $\begin{array}{l}Z=-2.941 \\
p=0.003\end{array}$ \\
\hline $\mathrm{FVC}^{*}$ & $95(48-125)$ & $84.5(36-136)$ & - & $\begin{array}{l}Z=-2.532 \\
p=0.011\end{array}$ \\
\hline $\mathrm{FEF}_{25-75}{ }^{*}$ & $71(17-120)$ & $55.5(15-136)$ & - & $\begin{array}{l}Z=-1.883 \\
p=0.060\end{array}$ \\
\hline
\end{tabular}

$\mathrm{FEV}_{1}$ : forced expiratory volume 1, FVC: forced vital capacity, $\mathrm{FEF}_{25-75}$ forced expiratory flow 25-75\%, CF: cystic fibrosis *Data is presented as median (min-max) 
Table II. Depression and Anxiety Symptom Levels.

\begin{tabular}{lllll}
\hline & $\begin{array}{l}\text { CF } \\
(\mathrm{n}=35)\end{array}$ & $\begin{array}{l}\text { Non-CF } \\
\text { bronchiectasis } \\
(\mathrm{n}=28)\end{array}$ & $\begin{array}{l}\text { Control } \\
(\mathrm{n}=40)\end{array}$ & \\
\hline CDI & $9(0-26)$ & $8(2-28)$ & $5(0-15)$ & $\mathrm{x} 2=11.324 \mathrm{p}=0.003$ \\
STAI-C (SA) & $34(21-48)$ & $34(24-48)$ & $30(21-47)$ & $\mathrm{x} 2=9.041, \mathrm{p}=0.011$ \\
STAI-C (TA) & $29(20-39)$ & $29(23-55)$ & $26(20-37)$ & $\mathrm{x} 2=7.304, \mathrm{p}=0.026$ \\
\hline
\end{tabular}

CDI: Child Depression Inventory, STAI-C/SA: State-Trait Anxiety Inventories for Children/ State Anxiety, STAI-C/TA: State-Trait Anxiety Inventories for Children/ Trait Anxiety

Data is presented as median (min-max).

performed the validity and reliability study in Turkish.

\section{Procedure}

The study was carried out in the Child and Adolescent Psychiatry Department of Hacettepe University İhsan Doğramacı Children's Hospital. It was approved by the Local Ethics Committee (FON 07/32). All subjects gave written assent and their parents' written informed consent for participating in the study. The SCIQ, HRS and the K-SADS-PL was carried out by a child and adolescent psychiatrist. Participating children and adolescents completed the CDI, STAI-C and the PedsQL-C and their mothers filled out the PedsQL-P.

\section{Statistical analysis}

The Statistical Package for the Social Sciences 17.0 was used for all statistic analyses. The Shapiro-Wilk test was used to determine the normality of the data. The three groups were compared with the Kruskal Wallis test. The categorical variables were compared with the Chi-square test and the Fisher's exact test. Spearman's correlation analysis was used for correlation analysis. A p value of less than 0.05 was considered statistically significant for paired comparisons and less than 0.017 for triple comparisons.

\section{Results}

This study included a total of 103 children and adolescents, 35 with CF, 28 with non-CF bronchiectasis, and 40 healthy controls. Of all participants, $45.6 \%$ were female and $54.4 \%$ were male, and their median age was 13 years (156 months). No significant differences were found between the three groups with regard to age, sex, SES, parental age and education level (Table I). Disease severity was described using $\mathrm{FEV}_{1}$ (>80 normal; 60-80 mild; 40-60 moderate; $<40$ severe). Accordingly, $74 \%$ of the CF group had normal $\mathrm{FEV}_{1}$ values, $20 \%$ mild, $6 \%$ severe. In the Non-CF bronchiectasis group $\mathrm{FEV}_{1}$ values were normal in $43 \%$, mild in $46 \%$, moderate in $7 \%$ and severe in $4 \%$. A comparison of the CF and non-CF bronchiectasis groups with respect to PFT revealed that theFEV ${ }_{1}$ and $\mathrm{FVC}$ values were significantly lower in patients with non-CF bronchiectasis (Table I).

All patients in the CF group had lung and pancreas involvement. In most patients (94.3\%) with CF, the onset of symptoms was before the age of 1 year while the corresponding figure for non-CF bronchiectasis group was $50 \%$. Chest physiotherapy was applied to all patients in the $\mathrm{CF}$ and non-CF bronchiectasis groups; and there was no significant difference between the CF and non-CF groups with respect to hospitalization rate, and the number and durations of hospitalizations (Table I).

\section{Psychiatric morbidity}

Eighty percent of children in the CF group were diagnosed to have at least one psychiatric disorder using the semi-structured clinical interview. These include, in the order of cumulative rates, anxiety disorders (54.3\%), depressive disorders (20\%), attention deficit hyperactivity disorder $(17.1 \%)$, enuresis nocturna (11.4\%), oppositional defiant disorder $(8.5 \%)$, adjustment disorder $(5.7 \%)$, obsessive compulsive disorder $(5.7 \%)$ and tic disorders $(2.8 \%)$. On the other hand, $50 \%$ of children in the non-CF bronchiectasis group diagnosed to have at least one psychiatric disorder, namely anxiety disorders $(31.2 \%)$, obsessive compulsive disorder (10.7\%), social phobia $(10.7 \%)$, enuresis nocturna (10.7\%), depressive 
Table III. Quality of Life Levels.

\begin{tabular}{lllll}
\hline & $\begin{array}{l}\text { CF } \\
(\mathrm{n}=35)\end{array}$ & $\begin{array}{l}\text { Non-CF } \\
\text { bronchiectasis } \\
(\mathrm{n}=28)\end{array}$ & $\begin{array}{l}\text { Control } \\
(\mathrm{n}=40)\end{array}$ & \\
\hline PedsQL-P & & & & \\
TH & $72.8(29.3-95.6)$ & $66.3(31.5-86.9)$ & $94.5(86-100)$ & $\mathrm{x}^{2}=65.193 \quad \mathrm{p}<0.001$ \\
PH & $71.8(28.1-100)$ & $59.3(31.2-84.3)$ & $96.8(87.5-100)$ & $\mathrm{x}^{2}=63.087 \mathrm{p}<0.001$ \\
PSH & $75(28.3-96.6)$ & $69.1(31.6-93.3)$ & $95(80-100)$ & $\mathrm{x}^{2}=53.985 \mathrm{p}<0.001$ \\
PedsQL-C & & & & \\
TH & $79.3(52.1-98.9)$ & $71.1(30.4-96.7)$ & $94.5(86.6-100)$ & $\mathrm{x}^{2}=54.752 \quad \mathrm{p}<0.001$ \\
PH & $78.1(42.8-100)$ & $65.5(28.1-93.7)$ & $93.7(87.5-100)$ & $\mathrm{x}^{2}=56.891 \mathrm{p}<0.001$ \\
PSH & $81.6(45-98.3)$ & $75.8(31.6-100)$ & $93.3(83.3-100)$ & $\mathrm{x}^{2}=46.461 \mathrm{p}<0.001$ \\
\hline
\end{tabular}

PedsQL-P:Pediatric Quality of Life Inventory Parent Version, PedsQL-C: the Pediatric Quality of Life Inventory Child Version, PSH: psychosocial scores, $\mathrm{PH}$ : physical health scores; $\mathrm{TH}$ : total health scores

Data is presented as median (min-max).

disorders $(3.6 \%)$, simple phobia $(3.6 \%)$, adaptation disorder $(3.6 \%)$ and tic disorders $(3.6 \%)$. In the healthy control group the rate of a psychiatric disorder was $20 \%$. The rates of psychiatric diagnosis were significantly different between the three groups $\left(\chi^{2}=26.936\right.$ $\mathrm{p}<0.001)$; the CF group had a significantly higher rate of psychiatric disorders than the two other groups $\left(\chi^{2}=6.300 \mathrm{p}=0.012 ; \chi^{2}=26.923\right.$ $\mathrm{p}<0.001)$; the rate of psychiatric disorders was also higher in the non-CF bronchiectasis group than the control group $\left(\chi^{2}=6.773 \mathrm{p}=0.009\right)$. The CF group had significantly higher rates of depressive disorders and oppositional defiant disorder; the non-CF bronchiectasis group had a significantly higher rate of anxiety disorders than the control group $\left(\chi^{2}=11.368 \mathrm{p}=0.003\right.$; $\chi^{2}=8.085 \mathrm{p}=0.018 ; \chi^{2}=6.071 \mathrm{p}=0.014$; $\left.\chi^{2}=9.937, \mathrm{p}=0.002\right)$. The rates of psychiatric diagnosis did not differ in terms of sex and $\operatorname{SES}\left(\chi^{2}=0.104 \mathrm{p}=0.747 ; \chi^{2}=2.452 \mathrm{p}=0.293\right)$.

There was a significant difference between the three groups with respect to depression and state anxiety symptoms determined with CDI and STAI-C (Table II). Paired comparisons between the groups revealed that the difference originated from the healthy control group, and there were no significant differences between the $\mathrm{CF}$ and non-CF groups $(\mathrm{p}=0.073 ; \mathrm{p}=0.004$; $p=0.004 ; p=0.07 ; p=0.016 ; p=0.008)$. The anxiety and depression symptoms in both groups were not related to patient's age, parental age or education level, or number and duration of hospitalizations. Depressive symptoms were positively correlated with the increasing number of medications used in both $\mathrm{CF}$ and non-CF bronchiectasis groups $(r=0.349, p=0.040 ; r=0.423, p=0.025)$. In the CF group, the depression symptoms were negatively correlated with $\mathrm{FEV}_{1}(\mathrm{r}=-0.354$, $\mathrm{p}=0.037), \operatorname{FVC}(\mathrm{r}=-0.462, \mathrm{p}=0.005)$, and $\mathrm{FEF}_{25-75}(\mathrm{r}=-0.382, \mathrm{p}=0.024)$ and again the trait anxiety symptoms showed a moderate negative correlation with $\mathrm{FEV}_{1}(\mathrm{r}=-0.455$, $\mathrm{p}=0.006)$, FVC $(\mathrm{r}=-0.554, \mathrm{p}=0.001)$ and $\mathrm{FEF}_{25-75}(\mathrm{r}=-0.349, \mathrm{p}=0.040)$.

\section{Quality of life}

The quality of life scores determined by both PedsQL-P and PedsQL-C were significantly different between the three groups (Table III). Paired comparisons between the groups revealed that the statistical significance was derived from the healthy control group $(\mathrm{p}<0.001)$, with the $\mathrm{CF}$ and non-CF bronchiectasis groups being similar with respect to total score, physical health score, and psychosocial health score of QOL reported by both children and mothers. $(\mathrm{p}=0.215 ; \mathrm{p}=0.566 ; \mathrm{p}=0.489)$.

In $\mathrm{CF}$ and non-CF bronchiectasis groups there were no significant correlations between sex, SES, hospitalization and quality of life levels reported by children or mothers. In the CF group, children with a psychiatric diagnosis had significantly lower child-rated QOL scores (PedsQL-CTH Z =-2.043 p=0.039; PedsQL-CPH $\mathrm{Z}=-2.065 \mathrm{p}=0.039$; PedsQL-CPSH $\mathrm{Z}=-1.882$ $\mathrm{p}=0.052)$. Separate analyes for depressive disorders and anxiety disorders revealed that in the CF group children diagnosed with 
Table IV. Factors Related to Quality of Life Levels in Cystic Fibrosis and Non-CF Bronchiectasis Groups.

\begin{tabular}{llllllll}
\hline & Age & CDI & $\begin{array}{l}\text { STAI-C } \\
\text { TA }\end{array}$ & $\begin{array}{l}\text { STAI-C } \\
\text { SA }\end{array}$ & FEV $_{1}$ & FVC & FEF $25-75$ \\
\hline CF & & & & & & & \\
PedsQL-P/TH & 0.002 & -0.314 & -0.283 & -0.050 & 0.212 & -0.023 & $0.378^{*}$ \\
PedsQL-P/PH & 0.039 & -0.208 & -0.264 & -0.077 & 0.183 & -0.071 & 0.211 \\
PedsQL-P /PSH & 0.047 & $-0.352^{*}$ & -0.284 & -0.040 & 0.210 & -0.031 & $0.436^{* *}$ \\
PedsQL-C/TH & 0.051 & $-0.608^{* *}$ & $-0.702^{* *}$ & -0.181 & $0.334^{*}$ & 0.266 & $0.479^{* *}$ \\
PedsQL-C/PH & 0.141 & $-0.427^{*}$ & $-0.540^{*}$ & -0.150 & 0.171 & 0.117 & 0.179 \\
PedsQL-C/PSH & 0.070 & $-0.659^{* *}$ & $-0.707^{* *}$ & -0.227 & 0.330 & 0.273 & $0.528^{* *}$ \\
Non-CF & & & & & & & \\
Bronchiectasis & & & & & & & \\
PedsQL-P/TH & 0.107 & 0.212 & 0.281 & $-0.537^{* *}$ & 0.241 & 0.194 & 0.114 \\
PedsQL-P/PH & -0.069 & 0.058 & 0.055 & -0.311 & 0.117 & 0.169 & 0.163 \\
PedsQL-P/PSH & 0.148 & $-0.478^{*}$ & $-0.656^{* *}$ & $-0.480^{* *}$ & 0.272 & 0.128 & 0.176 \\
PedsQL-C/TH & 0.113 & $-0.608^{* *}$ & $-0.702^{* *}$ & -0.181 & 0.064 & 0.093 & 0.145 \\
PedsQL-C/PH & 0.046 & -0.265 & $-0.651^{* *}$ & $-0.503^{* *}$ & 0.268 & 0.314 & 0.032 \\
PedsQL-C/PSH & 0.128 & $-0.582^{* *}$ & $-0.577^{* *}$ & -0.334 & 0.044 & 0.017 & 0.251 \\
\hline
\end{tabular}

PedsQL-P:Pediatric Quality of Life Inventory Parent Version, PedsQL-C: the Pediatric Quality of Life Inventory Child Version, PSH: psychosocial scores, PH: physical health scores, TH: total health scores, CDI: Child Depression Inventory, STAI-C/SA: State-Trait Anxiety Inventories for Children/ State Anxiety, STAI-C/TA: State-Trait Anxiety Inventories for

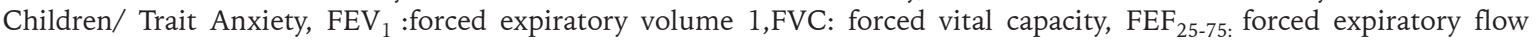
25-75\%, *: $<<0.05 ;{ }^{* *}: \mathrm{p}<0.01$

depressive disorders had significantly lower $\mathrm{TH}$ scores and PSH scores reported by both mothers and children $(Z=-2.826 \mathrm{p}=0.003$; $\mathrm{Z}=-2.888 \mathrm{p}=0.003 ; \mathrm{Z}=-2.455 \mathrm{p}=0.012 ; \mathrm{Z}=-$ $2.933 \mathrm{p}=0.092)$.

The correlation of QOL with anxiety and depression symptoms and PFT were also studied (Table IV). In the CF group, the PSH level reported by mothers and and all QOL levels reported by children showed a significant inverse correlation with depressive symptoms. A significant inverse correlation was found between QOL levels and trait anxiety symptoms in both the CF and the non-CF bronchiectasis groups. There was a significant positive correlation between $\mathrm{TH}$ scores reported by children and $\mathrm{FEV}_{1}$, and the $\mathrm{TH}$ and $\mathrm{PSH}$ scores reported by children and mothers and $\mathrm{FEF}_{25-75}$ (Table IV).

\section{Discussion}

This cross-sectional study compared QOL and related factors (psychiatric disorders, sociodemographic variables, disease severity) between children and adolescents with CF, and non-CF bronchiectasis, i.e. a separate, non- fatal chronic respiratory disorder, and healthy age-matched peers. A review of the literature did not identify any other study comprising these three groups in a similar study design.

Our study revealed that the psychopathology rates were higher in children with CF. Whereas previous studies have reported lower rates of psychiatric disorders in CF groups, the most commonly encountered disorders have been anxiety disorder and depression, as noted in our study. 2,8,9,30,31 Those studies have usually used either self-reported scales, parent reports or unstructured interviews. We believe that a greater rate of psychiatric diagnoses likely resulted from the structured interview technique used in our study and also the lack of adequate psychosocial support for these children in our country.

Depression and state anxiety symptoms were higher in both the CF and non-CF bronchiectasis groups. Studies employing selfreported scales in children and adolescents with CF have produced inconsistent results related to depression and anxiety levels or symptoms. ${ }^{2-4,32}$ In the only study where children 
and adolescents with non-CF bronchiectasis were studied, depression and state anxiety levels of these groups were comparable to those of the healthy group, although trait anxiety level was higher. ${ }^{33}$ Our findings are suportive of literature studies reporting higher depression and anxiety symptoms. Furthermore, higher depression and anxiety symptoms are consistent with the finding of high psychiatric comorbidity rate in both chronic disorders.

The main finding of our study is that the pediatric quality of life $\mathrm{TH}$ scores, $\mathrm{PH}$ scores, and PSH scores reported by both mothers and children were lower in children in the $\mathrm{CF}$ and non-CF bronchiectasis groups than those in the control group. So far, only two studies separately compared children with CF and non-CF bronchiectasis with their healthy peers. ${ }^{33,34}$ Similar to our results, those studies reported worse perception of quality of life among children with both $\mathrm{CF}$ and non-CF bronchiectasis.

Few studies have compared CF and other chronic disorders in terms of quality of life. One study used population sample as a healthy control group. ${ }^{35}$ In the study conducted by Sawyer et al. ${ }^{35}$ it was shown that CF and other chronic disease groups perceived health-related quality of life worse than the population sample in many domains. Previous comparisons of children with CF with other chronic disease groups have produced conflicting results. While it has been reported that children with CF had a better overall health perception and had a lower rate of emotional problems compared with children with chronic physical disorders, ${ }^{35,36}$ one study has reported worse psychosocial health and emotional functionality. ${ }^{13}$ Only one study found comparable results between $\mathrm{CF}$ and other chronic groups. ${ }^{36}$ Our findings indicate comparable QOL levels between CF and non-CF bronchiectasis groups. Considering that $\mathrm{CF}$ is a fatal disease with multiorgan involvement, it may be expected to have a deeper adverse impact on patients' QOL. However, lower $\mathrm{FEV}_{1}$ and FVC values in the non-bronchiectasis group but similar clinical characteristics such as number and duration of hospitalizations, and chest physiotherapy may have had unfavourably impact on quality of life scores in this group.

Among factors potentially affecting QOL, age and sex were not found to be correlated with QOL as reported by children and mothers. Although inconsistent results have been reported about these demographic variables in the literature, girls have been shown to have a worse QOL, and QOL was better at the prepubertal period.7,18,37-39 Our findings suggest that clinical characteristics and psychosocial variables may be more important for QOL rather than age and sex.

Although the negative effect of growth retardation and hospitalization on quality of life has been previously shown, this study failed to demonstrate their correlation with QOL. On the other hand, it indicated a positive correlation between quality of life and $\mathrm{FEV}_{1}$, $\mathrm{FEF}_{25-75}$ in the CF group. This finding supports the studies that have indicated the effect of respiratory function on QOL. Having said that, positive correlations between $\mathrm{FEV}_{1}$, $\mathrm{FVC}$, and $\mathrm{FEF}_{25-75}$ values and depression and anxiety symptoms are noteworthy for showing a possible relationship between pulmonary function and psychological status.

Our study demonstrated an association between a lower QOL and depression and trait anxiety symptoms in children with CF. Despite the lack of pediatric studies exploring the relationship between depression and anxiety symptoms and QOL in CF, adult studies have indicated a negative effect of anxiety and depression on various domains of QOL. ${ }^{16-18}$ Similar to adult studies, our study supported the hypothesis that depression and anxiety impact QOL. In parallel with these findings, psychiatric disorders also adversely affect children reported QOL. In CF, accompanying depression is closely related to overall and psychosocial quality of life. Importantly, the present study showed a relationship between a clinician-made diagnosis of depression with quality of life in CF. Most researchers have indicated that children with chronic disorders are at risk emotionally, socially, cognitively, and behaviorally. ${ }^{40}$ In particular, psychiatric comorbidities, particularly depression may unfavorably influence the life and disease management of patients with CF. Both anxiety and depression have been described as risk factors for a poor treatment compliance, increased mortality, and a lower chance of getting proper healthcare in chronic conditions. 5,16 Therefore, screening for 
psychiatric symptoms and disorders may aid in prevention of risk factors and development of treatment programs in $\mathrm{CF}$.

The main limitation of the present study is the small sample size. Additionally, sampling from a single center limits the generalizability of its principal findings. Finally, owing to its crosssectional nature, it falls short in evaluating temporary changes in quality of life between groups and establishing causal relationships. Its strengths include the use of a semi-structured interview, the use of evaluation tools with proven validity and reliability, and the inclusion of two separate control groups (a chronic disease group and healthy control group).

In conclusion, quality of life is poor in childhood in CF. This study is scientificly important for revealing that psychiatric symptoms/diagnoses are prevalent, adversely affecting quality of life of children and adolescents with CF. In these patients, an assessment of quality of life should be a part of the treatment, aiming at its improvement. In order to achieve this goal, psychiatric states of children and their parents should be evaluated and necessary interventions be applied. These patients should be treated by a multidisciplinary team. Psychosocial risk factors affecting quality of life in this disorder should be further studied in longitudinal studies involving larger populations.

\section{REFERENCES}

1. Castellani C, Assael BM. Cystic fibrosis: a clinical view. Cell Mol Life Sci 2017; 74: 129-140.

2. Bregnballe V, Thastum M, Schiotz PO. Psychosocial problems in children with cystic fibrosis. Acta Paediatr 2007; 96: 58-61.

3. Thompson RJ, Gustafson KE, Gil KM, Godfrey J, Murphy LM. Illness specific patterns of psychological adjustment and cognitive adaptational processes in children with cystic fibrosis and sickle cell disease. J Clin Psychol 1998; 54: 121-128.

4. Modi AC, Driscoll KA, Montag-Leifling K, Acton JD. Screening for symptoms of depression and anxiety in adolescents and young adults with cystic fibrosis. Pediatr Pulmonol 2011; 46: 153-159.

5. Quittner AL, Goldbeck L, Abbott J, et al. Prevalence of depression and anxiety in patients with cystic fibrosis and parent caregivers: results of The International Depression Epidemiological Study across nine countries. Thorax 2014; 69: 1090-1097.

6. Thompson RJ, Hodges K, Hamlett KW. A matched comparison of adjustment in children with cystic fibrosis and psychiatrically referred and nonreferred children. J Pediatr Psychol 1990; 15: 745-759.
7. Szyndler JE, Towns SJ, van Asperen PP, McKay KO. Psychological and family functioning and quality of life in adolescents with cystic fibrosis. J Cyst Fibros 2005; 4: 135-144.

8. Smith BA, Wood BL. Psychological factors affecting disease activity in children and adolescents with cystic fibrosis: medical adherence as a mediator. Curr Opin Pediatr 2007; 19: 553-558.

9. White T, Miller J, Smith GL, McMahon WM. Adherence and psychopathology in children and adolescents with cystic fibrosis. Eur Child Adolesc Psychiatry 2009; 18: 96-104.

10. Varni JW, Seid M, Rode CA. The PedsQL: measurement model for the Pediatric Quality of Life Inventory. Med Care 1999; 37: 126-139.

11. Habib AR, Manji J, Wilcox PG, Javer AR, Buxton JA, Quon BS. A systematic review of factors associated with health-related quality of life in adolescents and adults with cystic fibrosis. Ann Am Thorac Soc 2015; 12: $420-428$.

12. Bodnar R, Kadar L, Holics K, et al. Factors influencing quality of life and disease severity in Hungarian children and young adults with cystic fibrosis. Ital J Pediatr 2014; 40: 50.

13. BodnárR, Kádár L, Szabó L, Hernádi M, Mikóczi M, Mészáros Á. Health related quality of life of children with chronic respiratory conditions. Adv Clin Exp Med 2015; 24: 487-495.

14. Gee L, Abbott J, Conway SP, Etherington C, Webb AK. Quality of life in cystic fibrosis: the impact of gender, general health perceptions and disease severity. J Cyst Fibros 2003; 2: 206-213.

15. Abbott J, Morton AM, Hurley MA, Conway SP. Longitudinal impact of demographic and clinical variables on health-related quality of life in cystic fibrosis. BMJ Open 2015; 19: 5:e007418

16. Havermans T, Colpaert K, Dupont LJ. Quality of life in patients with Cystic Fibrosis: association with anxiety and depression. J Cyst Fibros 2008; 7: 581-584.

17. Yohannes AM,Willgoss TG,Fatoye FA,Dip MD,Webb K. Relationship between anxiety, depression, and quality of life in adult patients with cystic fibrosis. Respir Care 2012; 57: 550-556.

18. Riekert KA, Bartlett SJ, Boyle MP, Krishnan JA, Rand CS. The association between depression, lung function, and health-related quality of life among adults with cystic fibrosis. Chest 2007; 132: 231-237.

19. Borawska-Kowalczyk U, Bodnar R, Meszaros A, Sands D. Comparison of health-related quality of life among children with cystic fibrosis and their parents in two Eastern European countries. J Cyst Fibros 2015; 14: 798-804.

20. Oliver NK, Free LM, Bok C, McCoy SK, Lemanek LK, Emery FC. Stigma and optimism in adolescents and younga adults with cystic fibrosis. J Cyst Fibros 2014; 13: 737-744.

21. Çengel Kültür SE, Ünal MF, Özusta Ș. Alkol bağımlılığı olan babaların çocuklarında psikopatoloji. Türk Psikiyatri Dergisi 2006; 17: 3-11.

22. Kovacs M. Rating scale to assess depression in school 
aged children. Acta Paedopsychiatr 1981; 46: 305-315.

23. Öy B. Çocuklar için depresyon ölçeği: Geçerlik ve güvenirlik. Türk Psikiyatri Dergisi 1991; 2: 132-136.

24. Spielberger CD. Manual for the state-trait anxiety inventory for children. Palo Alto: Consulting Psychologists Press, 1973.

25. Özusta S. Turkish standardization, reliability and validity of State Trait Anxiety Inventory for children. Turk J Psychol 1995; 10: 32-44.

26. Kaufman J, Birmaher B, Brent D, et al. Schedule for affective disorders and schizophrenia for school-age children-present and lifetimeversion (K-SADS-PL): initial reliability and validity data. J Am Acad Child AdolescPsychiatry 1997; 36: 980-988.

27. Gökler B, Ünal F, Pehlivantürk B, Çengel Kültür E, Akdemir D, Taner Y. Okul çağı çocukları için duygulanım bozuklukları ve şizofreni görüşme çizelgesi - şimdi ve yaşam boyu şekli-Türkç uyarlamasının geçerlik ve güvenirliği. Çocuk ve Gençlik Ruh Sağlığı Dergisi 2004; 11: 109-116.

28. Çakın Memik N, Ağaoglu B, Coskun A, Karakaya I. Çocuklar için yaşam kalitesi ölçeğinin 8-12 yaş çocuk formunun geçerlik ve güvenirliği. Çocuk ve Gençlik Ruh Sağlığı Dergisi 2008; 15: 87-98.

29. Cakın Memik N, Agaoğlu B, Coskun A, Üneri OȘ, Karakaya I. Çocuklar için yaşam kalitesi ölçeğinin 1318 yaş ergen formunun geçerlik ve güvenilirliği. Türk Psikiyatri Dergisi 2007; 18: 353-363.

30. Thompson RJ Jr, Hodges K, Hamlett KW. A matched comparison of adjustment in children with cystic fibrosis and psychiatrically referred and nonreferred children. J Pediatr Psychol 1990; 15: 745-759.

31. Thompson RJ, Gustafson KE, Hamlett KW, Spock A. Psychological adjustment of children with cystic fibrosis: the role of child cognitive processes and maternal adjustment. J Pediatr Psychol 1992; 17:741-755.
32. Pearson DA, Pumariega AJ, Seilheimer DK. The development of psychiatric symptomatology in patients with cystic fibrosis. J Am Acad Child Adolesc Psychiatry 1991; 30: 290-297.

33. Bahali K, Gedik AH, Bilgic A, et al. The relationship between psychological symptoms, lung function and quality of life in children and adolescents with noncystic fibrosis bronchiectasis. Gen Hosp Psychiatry 2014; 36: 528-532.

34. Kianifar HR, Bakhshoodeh B, Hebrani P, Behdani F. Qulaity of life in cystic fibrosis children. Iran J Pediatr 2013; 23: 149-153.

35. Sawyer MG, Reynolds KE, Couper JJ, et al. Healthrelated quality of life of children and adolescents with chronic illness-a two year prospective study. Qual Life Res 2004; 13: 1309-1319.

36. Ingerski LM, Modi AC, Hood KK, et al. Health-related quality of life across pediatric chronic conditions. J Pediatr 2010; 156: 639-644.

37. Groeneveld IF, Sosa ES, Pérez M, et al. Health-related quality of life of Spanish children with cystic fibrosis. Qual Life Res 2012; 21: 1837-1845.

38. Cohen MA, Ribeiro MÂ, Ribeiro AF, Ribeiro JD, Morcillo AM. Quality of life assessment in patients with cystic fibrosis by means of the Cystic Fibrosis Questionnaire. J Bras Pneumol 2011; 37: 184-192.

39. Hegarty M, Macdonald J, Watter P, Wilson C. Quality of life in young people with cystic fibrosis: effects of hospitalization, age and gender and differences in parent/child perceptions. Child Care Health Dev 2009; 35: 462-468.

40. Barlow JH, Ellard DR. The psychosocial well-being of children with chronic disease, their parents and siblings: an overview of the research evidence base. Child Care Health Dev 2006; 32: 19-31. 